\title{
A DNA Nanoswitch as a Biosensor
}

Amy H. Buck ${ }^{1 *}$, Colin J. Campbell ${ }^{1,3^{*}}$, Paul Dickinson ${ }^{1 *}$, Christopher P. Mountford ${ }^{2}$, Hélène C. Stoquert ${ }^{1}$, Jonathan G. Terry ${ }^{4}$, Stuart A.G. Evans ${ }^{3}$, Lorraine M. Keane ${ }^{1}$, Tsueu-Ju Su ${ }^{2}$, Andrew R. Mount ${ }^{3}$, Anthony J. Walton ${ }^{4}$, John S. Beattie ${ }^{1}$, Jason Crain ${ }^{2}$ \& Peter Ghazal ${ }^{1}$

*These authors contributed equally to this work

${ }^{1}$ Division of Pathway Medicine, University of Edinburgh, EH16 4SB, UK

${ }^{2}$ School of Physics University of Edinburgh, Edinburgh, EH9 3JZ, UK.

${ }^{3}$ School of Chemistry University of Edinburgh, Edinburgh, EH9 3JJ, UK.

${ }^{4}$ Institute for Integrated Micro and Nano Systems, University of Edinburgh, Edinburgh, EH9 3JF, UK

AUTHOR EMAIL ADDRESS p.ghazal@ed.ac.uk, colin.campbell@ed.ac.uk

Figure S1: Comparison of FRET ratios obtained in solution versus using gelFRET at 5.0 $\mathrm{mM} \mathrm{MgCl} 2$ at $1 \mu \mathrm{M}$ probe and $5 \mu \mathrm{M}$ of the matched and mismatched targets (gelFRET data is the same as depicted in Figure 2b).

Figure S2: FRET ratios for each probe/target complex $(1 \mu \mathrm{M}: 5 \mu \mathrm{M})$ as a function of $\mathrm{MgCl}_{2}$, measured in solution. The arrows indicate the two concentrations of $\mathrm{MgCl}_{2}$ used for further measurements.

Figure S3: gelFRET of $1 \mu \mathrm{M}$ probe with $5 \mu \mathrm{M}$ matched and mismatched targets at $100 \mu \mathrm{M} \mathrm{MgCl}_{2}$. 
Figure S4: FRET ratios at $5.0 \mathrm{mM} \mathrm{MgCl} 2(1 \mu \mathrm{M}: 5 \mu \mathrm{M}$ probe:target $)$ and $0.1 \mathrm{mM} \mathrm{MgCl} 2$ ( $1 \mu \mathrm{M}: 5 \mu \mathrm{M}$ probe:target and $50 \mathrm{nM}: 100 \mathrm{nM}$ probe:target). Error bars shown are standard deviations $(n=3)$. Data are the same as shown in Figure 3 but they have not been normalized. 